\title{
Female Subjectivity in Lisa See's Snow Flower and the Secret Fan
}

\author{
Neurina Fajriyatul Islamiyah \\ English Literature, Faculty of Languages and Arts \\ Universitas Negeri Surabaya \\ Surabaya, Indonesia \\ neurinai1@mhs.unesa.ac,.id
}

\author{
Much. Koiri \\ English Literature, Faculty of Languages and Arts \\ Universitas Negeri Surabaya \\ Surabaya, Indonesia \\ muchkoiri@unesa.ac.id
}

\begin{abstract}
In a society where the patriarchal system exists, generally, women are put below men and have limited access and freedom. They are being oppressed and controlled. The oppression limits the women moves, thus, they exhibit what is called as female subjectivity. In the novel Snow Flower and the Secret Fan, Lisa See tried to depict the female subjectivity by the female characters, especially from Lily and Snow Flower. Female subjectivity allows women to be able to think, to speak, and to act for themselves. Women's oppression is the contributing factor of female subjectivity; women's exploitation, women's marginalization, powerlessness, and violence. As a result of female subjectivity, the female characters display the acts of resistance. Therefore, the purpose of this study is to find out the depiction of female subjectivity and the contributing factors to female subjectivity. This study uses post-structural feminism theory, the concept of subjectivity, and the concept of resistance. Thus, the study showed that the female subjectivity happens as a way to acquire selfhood and personality. The trigger of female subjectivity lies on women's oppression experienced by the female characters. The women do silence resistance through silent rebellion and nu shu writing as it gives the women voices they need and to keep a record of women's experiences.
\end{abstract}

Keywords-post-structural feminism; female subjectivity; oppression; resistance

\section{INTRODUCTION}

This study tries to depict the female subjectivity and its contributing factors in Lisa See's Snow Flower and the Secret Fan. See's novel is chosen because her novel talks about how oppressed women in patriarchal society in China are able to acquire what is so called subjectivity.

Snow Flower and the Secret Fan-written by Lisa See, an American born in Paris on February $18^{\text {th }} 1955$ and spent most of her years in Chinatown, Los Angeles-tells the story of two girls who embark on a life journey as Chinese women in their society. It is set in $19^{\text {th }}$ century of China during the reign of Emperor Daoguang. Lily and Snow Flower begins their friendship by becoming laotong match, and throughout their lives, they have experienced joy and sorrow as a girl, and at later time, a woman and a wife. They record their experiences through secret writing called $n u$ shu for at that time, unlike men, women in traditional China do not have the rights to get proper education.

See's novel depicted the treatment of women in Chinese society where woman should only bear sons for it makes their life fortunate and easier and loved by their husband and in-law families. The value of women depends on how many sons she has and her obedience toward her husband's family. Not only that, the foot-binding process is also a sign that Chinese women's life is under the control of men and society since their childhood.

These kind of women's oppression are limiting the space for Chinese women to speak up about their condition. They are greatly oppressed by the society and it leaves small room to resist. The resistance is triggered by women's consciousness of subjectivity in which women allowing themselves to have full control of what they think and what they should do. One of ways to break free from the confinement was through $n u-s h u$ writing. In here, $n u$-shu writing served as a path of resisting the domination of men.

Theoretical framework that used in this study is poststructural feminism. This study also uses the concept of subjectivity and the concept of resistance. To question women as the subject of feminism, it may prove to preclude the possibility of feminism as representational politics. The identity of feminist subject ought not to be the foundation of feminist politics if the subject's formation is dealt within a field of power. However, in a sense that the subject of 'women' is nowhere (unavailable), the representation will make sense for feminism (Butler, 1999, p. 9).

Further, Irigaray asserts that when women challenge the nature and form of political life, play of powers and power relations, they are in fact working toward the modification of women's status. The aim of the movement is simply to change the distribution of power, leaving the power itself, and they will re-subjecting themselves to a phallocratic order. However, the latter one may constitute subtly concealed women's exploitation (1985, p.81).

Weedon in Morton and Zavarzadeh (1991, p. 50) states that post-structural feminist critics pinpointed the emphasis in discussions on women's experience. Women are expected to 
raise consciousness by talking with other women about experiences, recognizing similarities and looking for the social causes. Feminists moves to extend politics from outside into domesticity and the realm personal relationship. Early feminist movements believe that expressing women's experience is a way of speaking the unvoiced or suppressed reality of what is it to be a woman. This point of view relies on experience and the language in which it is expressed.

Mansfield (2000, p. 6) proposes that subjectivity is primarily an experience, and remains permanently open to inconsistency, contradiction and unself-consciousness. Which means that every single experience remains forever to ourselves due to dogma or norm in a society that can make one single thing becomes homogenized. Subjectivity offers to see the world based solely on our own experiences and as a way to represents self-recognition which sometimes pleasurable and reassuring, but never being the final restingplace. According to post-structuralism, subjectivity is constantly negotiated, constituted, and reconstituted in discourse every time an individual thinks or speaks (Soza, 2014, p. 13).

Any kind of resistance is a form of unwillingness towards the advocated, or inculcated, repertoire (Even-Zohar, 2002, p. 48). People who are oppressed and dominated will likely perform the act of resistance for they think and feel that the particular condition is not fair to them. From here, the intention of doing resistance and shall the resistance be visible and recognized marks the discussion span of resistance. Resistance's recognition depends on the goal of the resisters. Some do it to get recognition, while other conceal it intentionally (Hollander and Einwohner, 2004, p. 540).

There is also a concept of 'everyday resistance' that was first introduced by James Scott in 1985. It is the way people act in their everyday lives and the resistance is not easily recognized like demonstration. But it is quite, disguised, and seemingly invisible. Such resistance is done routinely and often not being recognized by society (Vinthagen and Johansson, 2013, pp. 2-4, 10).

This study also looks at women's condition in China in $19^{\text {th }}$ century. The background of socio-economic as well as the culture and tradition which present in ancient China will assist this study to asses and to analyze the female subjectivity as experienced by Lily and Snow Flower in Lisa See's Snow Flower and the Secret Fan. It will look into how Chinese society defines the role of women. This background of women in Chinese society also serves as the ground basis to examine the resistance done by Lily and Snow Flower as a result of their female subjectivity.

In China, Confucius teaching had not favorable word for women. As cited by David and Vera Mace in Man Rhim (1982, p. 1), Confucius teaching is based on patriarchal system, filial piety, and ancestor worship. In this system, woman had to obey and not to question anything. Throughout her life, woman needs to obey her father when she is a daughter, when married she obeys husband, and when widowed obeys her son. The idea of traditional Chinese cosmology where male is sees as having positive energy and female represents negative energy and aura is reinforcing the Confucius teaching.

The situation of the illustration above suggests that China was or perhaps still is a male-centered society. The differential treatment of men and women had been present over the centuries and it looks like women are often, if not always, being overlooked. This clearly gives the fact that women had always been possessed and dominated throughout their lives by men.

\section{METHOD}

Research method used in this study is post-structural feminism applied into the elements of feminism which are presented in Snow Flower and the Secret Fan. The data source is the novel entitled Snow Flower and the Secret Fan written by Lisa See and was published in 2005 by Random House New York. The data are in the form of direct/indirect quotations, phrases, and dialogues.To obtain the data, close reading will be done to analyze and to classify the data needed in the form of the quotations and/or statements which are present in the novel.

This study has several analytical steps. First, close reading on Lisa See's Snow Flower and the Secret Fan is done to classify and deal with the text. Second, data is classified based on the statement problem. They are to reveal the depiction of female subjectivity happened to Lily and Snow Flower and to reveal the contributing factors of female subjectivity. Third, using post-structural feminism as the theoretical framework and the concept of subjectivity to depict the female subjectivity. Fourth is revealing the contributing factors to female subjectivity. Here the concept of resistance will be used to justify why female subjectivity happens. Fifth is answering the statement problems and draw the conclusion.

\section{DISCUSSION}

\section{A. Depiction of Female Subjectivity}

The first problem is about female subjectivity. In here the depiction of female subjectivity includes the behavior, the thought, the action, and the spoken matters done by the female characters.

All of Third Sister's screams of the past weeks took on a different meaning. Did she know on that first day that something bad might happen? Was that why she had resisted? Had Mama made some terrible mistake in her haste? Had Third Sister's blood poisoning been triggered by wrinkles in her bindings? Was she weak from bad nutrition as Madame Wang claimed I had been? What had she done in her previous life to deserve this punishment now? (See, 2005, pp. 31-32)

In the past time, Chinese girls during certain age are bound to have their feet bounded. As a symbol and hope of attracting happy marriage and prosperous life, Lily's family, especially mother and aunt, decides to do the foot-binding ritual for three girls on the house, Lily, Third Sister, and Beautiful Moon. However, as they are poor and uneducated women, little did the mother know that the process could fatally damage the feet of the children, even the slightest mistake on the process could 
lead to death. All that matters to them is do the binding correctly to attain perfect size of feet so that their daughters' future are reassured.

Lily, who has learnt that she would later, becomes a woman of influence, accepts the reality and endures the pain. She hopes that she will be rewarded exactly as she is told. She does not complain nor protest. When mother orders her to cross the room back and forth to make the toes broken quickly, she just quietly does as she says. It is different from Third Sister. She insists that she won't bind her feet, but mother cusses at her and treats her harder and harsher. She cries and screams everyday but no one took pity in her until her legs getting red streak and she is down with high fever.

Deep down, Lily already has her suspicion that from the beginning, perhaps, Third Sister already knows something bad might happen during the foot-binding process. When she said 'Had Mama made some terrible mistake in her haste?', it is clear that she thinks of her mother's doing as the trigger of the calamity. Although she is not supposed to say what she thinks out loud, she questions the harsh acts of her which results in Third Sister's suffering. She also mentions 'wrinkles in her binding' which indicates that the binding is loose and not done properly. If it is tight and proper, such thing as blood poisoning is impossible to begin with. In here, Lily seems to condemn the mother of her wrongdoing.

Having grown up in an environment that forbid women to become talkative and critical, Lily have accustomed hearing things like 'women are useless creature' or 'women's worth are depending on their sons'. Eventually, she internalizes the values into herself. Besides those thing, she is also able to examine the situation of her surrounding and carefully picking up the valuable lessons or simply takes the good manners to be implemented later on in her life. She is a kid, but her mind already matured like a woman. She is just a little daughter, but her eyes already envisioned her future far from the present time.

The story showed me how the value of a girl-or womancould shift from person to person. It also offered practical instruction on how to care for a loved one after death-how a body should be handled, what constituted proper eternity garments, where someone should be buried. My family had tried their best to follow these rules, and I would too, once I became a wife and mother. (See, 2015, p. 39)

One time when the women of the family gather together, aunt and her sworn sisters are reciting and old tale of "The Story of the Woman with Three Brothers". Lily, despite hearing the tale for many times, still love listening to the story. It reminds her of the death of Third Sister and grandmother. Being a woman in Chinese society is not easy. The sentence of 'the value of a girl-or woman-could shift from person to person' means that girl or woman is seen differently in the society, or in the family, to be exact. The hidden moral is that no matter how the relationship works within the family, when one dies, the others should take good care of it.

There are three main points to do to become a filial child. First is caring for families, second is to present proper garment for the dead, and third is to bury the dead in the righteous place. Although this seems easy, according to Lily's family circumstances, to do the last two is the most difficult one. They are a poor family, and given two death situation, Baba, as the head of the family, needs to sort things out in regard of the funeral procession. Lily witnesses all the happenings, and she learns that her family had done their best to accommodate the tradition.

Madame Wang, the matchmaker, proposes to Lily's family to find a laotong match for Lily. Laotong match is a match between two girls that bound them to love each other until death. Its bond is stronger than marriage and couldn't tear apart. Basically, laotong match is examined through the sameness of name characters, birth month, Chinese zodiac, and the family circumstances. Laotong match is supposed to support and comfort, and to learn the differences of the partner's ways of life in order to see life wisely.

Women who talk a lot and express their minds freely is considered as a troublesome one. Snow Flower is talkative, whereas Lily is quiet. Knowing that Lily is quiet, Snow Flower takes the chance to tell her that she is okay with her being quiet. 'I don't care if you're quiet' indicates that Snow Flower does not mind seeing Lily spoke only little. It can also mean that she likes Lily for it. As a girl who loved talking, what Snow Flower needs is ears to listen without asking or questioning much. And perhaps, Lily fits into the criteria so Snow Flower grows intimate companion and being fond to her. Another thing to note is that when Snow Flower speaks that she get troubles of her talking, this indicates that girls or women in that era have the limited space to speak up their minds. The society constructs women as the second role, it means that women are not allowed to display some sort of interest outside their inner realm.

'I often don't think before I speak' shows that Snow Flower has the spontaneous ability to just speak without considering the consequences that may happen because of her words. She is not afraid of anything, she embraces her curiosity proudly and even admits that she had taken into problem. Snow Flower is a strong girl for her age. She clearly displays her bravery and made remarks that this is what she is; talkative, curious, and risk taker.

Meanwhile, she expresses her thought of Lily becoming an ideal wife just based on the words choice. For her, Lily might be the best ideal wife because she is meek and docile. The ideal wife is those who do not speak a lot. Although it does feel ambiguous, Snow Flower is kind of expressing the thought that she may not be an ideal wife herself. She might question a lot of things and in opposite, Lily would be just do anything as she told to. She just thought that she probably won't fit into the criteria which constituted the ideal of a wife.

Sitting in the upstairs chamber, I planned and schemed, but I was scared. Simplicity seemed best--I would pick up Snow Flower in my palanquin on my way home--but it would also be the easiest way to get caught. ..... but by the time the festival arrived, I had built up my bravery to the point I thought we might succeed. (See, 2005, pp. 160-161) 
Lily thinks of a plan to meet Snow Flower secretly. She has to do it without the knowledge of mother in law. She needs to execute the plan carefully or she will face big trouble. This act remarks her bravery to do thing for herself. Although she knows the risk, she still boldly take the action. In here, See expresses how Lily has her own authority to react to the problem. She is being independent and does not rely to others to look for an answer.

She tries to experimenting the plan to see whether it will work well or not. If it is, she will probably do the same thing later on when she wants to meet Snow Flower. The mother in law's reason to forbid Lily meeting Snow Flower is to prevent Snow Flower's presence to influence her grandson. She clearly sees Snow Flower as an unworthy person to be with her daughter in law. Judging someone because of their lack of status is considered as an act of marginalization. Lily does not want to marginalize her laotong just because she is a poor. Thus, she tries to escape from what mother in law says about Snow Flower and rebels through this way.

She laughed into the darkness. "No one gets sick from bed business. It only gives you pleasure. I work hard all day for mother in law. Do I not deserve the delights of night? And, if I have another son, I will be happier still." (See, 2005, p. 164)

In this case Snow Flower expresses her opinion of intimate moment between husband and wife. It is taboo to speak of it, but Snow Flower does not see that as a wrong thing to do. By speaking of her mind, she delivers the idea of her intimate moment and why she likes that. She admits she enjoys doing bed business because it gives her pleasure and as a chance to break away from reality for a little while.

When she says 'Do I not deserve the delights of night?", she questions whether it is not okay to talk very openly about the intimate relation. In front of Lily, she is able to pour out her thoughts freely since she knew Lily will listen to her. Snow Flower is all alone in the husband's house, no one talks to her, no one shares stories with her, and most importantly, no one listens to her grudges. Their laotong relationship allows them to talk about everything, even the most private talk.

"Only I will leave this room," I told my children. "Elder Brother is in charge of you when I am not here. You are to obey him in all ways. (See, 2005, p. 177)

The drought comes in Tongkou makes the crops cannot be harvested. To make thing worse, the typhoid outbreak pins down people and death come along with it. Lily's husband gone to Guilin to buy salt, leaving Lily alone at the house. Without husband, Lily feels anxious, restless, unprotected and powerless. She needs to do everything to protect her children at all cost. Lily knew the situation in the household is really bad, but she cannot abandon her duty as daughter in law. She has to put aside her fear and runs the house.

Lily could not care less about what happens to the other in laws as they all locked themselves up in their rooms. The outbreak is terrifying and Lily knows it is only a matter of time to see one of them succumbs to the deadly disease. She won't let the typhoid affects her children. She would rather be the victim than seeing her kids dying. Motherly instinct takes over the way she thinks. She uses all her strength to think of the best way to stay alive.

I stared at the chicken. My mouth salivated and my stomach grumbled, but for the first time in my married life I turned a deaf ear. I did not answer. (See, 2005, p. 178)

During her married life, Lily never disobeys what her mother in law says. However, this time, she does differently. For the very first time, she does not listen to her mother in law for the sake of her children's health condition. She stands for what she believes is the right thing to do. Her brave act shows that even though she is still subjected to serve her in laws and family, she does not abandon her children. She puts her children before her and implies that if something bad happens to her children, it is more likely that she won't forgive herself. Her not answering in law's question means that she has a different idea and approach to tend the kids. It can also be inferred that she cannot trust and believe other people more than her own. She exhibits a strategy of surviving.

\section{B. Contributing Factors to Female Subjectivity}

There must be factors triggering the women to awaken their subjectivity. In the novel it is mainly because of women's oppression. Young in Heldke and O'Connor (2003, pp. 37-60) stated that there are five types of oppression; exploitation, marginalization, powerlessness, cultural imperialism, and violence. Yet, there are four types of women's oppression that can be seen in the novel.

\section{Women's Exploitation}

There are two notable matters in the novel which manifest the women's exploitation. The first one is women's labor inside and/or outside the house, the second one is sexual exploitation. It has been known all along that even though a woman works to support her family to earn some money, still, she is expected to do houseworks too. Men expect women to be able to perform both duties as working women and house wife and demand perfection.

In the novel, Lily married to a noble family in which she was not allowed to do work outside home. Her works was only around serving his husband or obeying her in-laws. Her main labor was to take care of the household and to learn how to be the proper lady.

“... You know how to spin cotton and wool, weave, sew, and embroider. You know how to cook, clean, wash, keep tea always warm and ready, and light the fire in the hearth..." (See, 2005, p. 109).

Houseworks for women is considered really important, especially when a daughter marries and has to move to the husband's house. The quotation above is stated by Lily's mother, day before her marriage. "Cook, clean, wash, keep tea ready, light the fire" are all works that generally done by women in a household. Women are expected to master the art of becoming the queen of the kitchen. In this case women are 
exploited to do the house chores and of course to master women's craft such as embroidery. By doing all the house chores, it shows that women are embodied as the 'servant' of the house and it highlights the view of traditional gender role of women.

\section{Women's Marginalization}

Both Lily and Snow Flower are marginalized since their childhood. As daughters, they are treated as 'worthless child' and do not have the right to join the activities of men. At their home, there is room only for women and men are not allowed to enter. In the room, women can speak freely and did things like embroidery or telling stories to other girls/women.

My family home was typical in the sense that it had two stories and faced south. A room upstairs was designated for women's gathering and for unmarried girls to sleep. (See, 2005, p. 9)

The different treatments between men and women is reflected in the novel through the description of separated rooms of men and women, as seen in the quotation above. That typical women's chamber does exist in every house, be it rich household or household of farmers. This separation of room indicates that women had no right to participate in men's talk. As it designated for women's gathering and for unmarried girls to sleep, it can be inferred that such room symbolizes a cage of the birds. The girls are the birds, and the room is the cage. By caging the girls in the room, men have the authority to forbid and limit every source of knowledge or news that can be heard by the girls. Women's space is only in their designated room. They become submissive and just do as they told. Women are seen less important and less 'human'.

\section{Powerlessness}

Powerlessness comes in the form of foot-binding. Girls around six have to undergo foot-binding to determine their beauty. The desired feet is about three inches and it is said that those who possess such feet will be lucky for the rest of her life. Foot-binding is compulsory for family who wanted to send their daughters to a better family. Its process is really painful and sometimes one can die during the process. Nevertheless, foot-binding as the beauty standard bounded women to obey and not to question the reasons why they have to bind their feet. Women have no power to reject the tradition.

The poorest girls don't have their feet bound at all. We know how they end up. They are either sold as servants or they become "little daughters-in-law — big-footed girls from unfortunate families who are given to other families to raise until they are old enough to bear children. (See, 2005, p. 17)

Foot binding is seen as a step to attain beauty and to achieve respect in society. If a women successfully obtain the perfect size of feet after doing the binding, she will likely be praised by the people and her chance to have a better life is mostly guaranteed. The feet symbolizes the intimate part of a men, thus, men find it attractive to have women with feet bounded. Thus, the practice of foot-binding is degrading women for women are just object of men's pleasure in the society.

\section{Violence}

In the novel, only Snow Flower experiences violence, sexual violence and physical abuse. During her married life, she often gets beaten by her husband. She receives physical abuse even though she does nothing wrong. All of the beaten is mostly triggered by Snow Flower's failure to conceive a son, or that she gives birth to a daughter. Snow Flower's husband was a temperamental man. He would easily beat her and acted as if nothing happened afterwards. Lily witnessed his brutality when Snow Flower's second son died all of a sudden.

When Snow Flower asked where her son was buried, the butcher turned and hit her with such ferocity that she flew back a couple of meters and landed with a thud onto the hard-packed snow. He proceeded to beat her so badly that she miscarried in a violent gush of black blood that stained the icy slopes throughout our campsite. (See, 2005, p. 207)

Losing a son may be the hardest experience for a man, and in this novel, Snow Flower's husband, the butcher, is in disbelief, knowing that his precious son has died. Since he is valuing son more than daughter and he does not really have anything to channel his anger, the butcher beats Snow Flower. When he hit her with such ferocity, the husband is really angry, and perhaps, disappointed. The mixed feelings get him to beat his wife simply because he does not know who can be accused and responsible for his son's death. He thinks that his wife is the sole cause of the death. His violence act shows that in patriarchal society in traditional China, son is everything, and accusing even beating the wife for not being able to protect the son is seen as a normal behavior of men.

\section{Resistance as the Result of Female Subjectivity}

Resistance happens when one wants to oppose something or someone, that he or she is being suppressed or dominated by person or society. In the novel, the resistance occurs as the result of patriarchy practice and women's oppression. They needs to do everything that they are told to and practicing the Three Obediences and Four Virtues. Due to great oppression, it is only natural that they will likely find a way to break free from it. The characters choose the so called silence resistance.

There are two different forms of resistance. The first one is the act of silent rebellion and the second one is through $n u$ shu writing.

I wanted to accuse my family, but for my own welfare I still needed to follow the rules of filial piety. So I rebelled in small ways, isolating myself emotionally and physically as best I could. (See, 2005, p. 135)

Lily feels betrayed by her family for they hid the secrets of Snow Flower's family and condition. She also feels that she is 
being used by them. In fact, Lily is indeed being oppressed in her own family. Her mother takes advantage of her daughter to rise the family's wealth. She puts Lily as a bait for incoming fortune and good luck by telling lies to her.

After learning the truth, Lily takes revenge by doing silence resistant. Her way of avoiding her family, and not wanting to talk to them can be seen as a sign that she wants to teach her family a lesson. She changes to a cold person. She even knows how to put an act in front of family members. Her action symbolizes her disagreement toward her family's behavior. Her family has no right to conceal the truth about her laotong, a person that she loves dearly and close to her heart. She would rather accept the reality and still able to love Snow Flower unconditionally.

The women use $n u$ shu writing as a tool to perform silence resistance. $\mathrm{Nu} s h u$ is the secret writing of women. They invented it by recomposing the men's writing. Yet, different from men's writing, nu shu writing is only composed of the phonetic sounds. Men can hardly recognize it as a form of writing. Because of its secret, many women use $n u$ shu to write about their personal experiences, it is ranging from their longing to natal family, or to tell about their new life in husband's house.

"Remember, girls," Aunt said. "Not all men are emperors, but all girls marry out. Yuxiu invented $n u$ shu for the women in our country to keep our ties to our natal families." (p. 71)

One time, Aunt tells the story behind the invention of $n u$ $s h u$. She states that $n u$ shu serves as a connection tool between daughter and natal family. From aunt's statement, it can be concluded that $n u$ shu is the connecting bridge. When daughter goes into the husband's, her communication with the parents is limited, thus, by writing $n u$ shu, she can expresses what she feels and what she experiences during her life as a wife and daughter in law.

Resisting through $n u s h u$ is seen as a safe way to rebel. It is silent and does not need a lot of commotion. Although it does not really ease the hardship experienced by the women, it is still regarded as a way to soothe those women's feeling, in the hope that they may find strength in it.

With her bold act, I realized the true purpose of our secret writing. It was not to compose girlish notes to each other or even to introduce us to the women in our husband's families. It was to give us a voice. (See, 2005, p. 160)

It is clear that $n u \operatorname{shu}$ is used to give the women voices they need. Since they have difficulties to speak what they really want, the only way is to channel the thoughts through $n u$ shu writing. As secret writing, $n u$ shu becomes the barrier from men's interference. Men surely cannot read $n u$ shu and it gives advantages to women so that they are able to pour out the secrets on the fans. It is also seen as a way to bringing out women's opinions without being afraid of the consequences.
It is mostly impossible for the women in the household to act as they want, and it is even harder to have someone to discuss and talk about a lot of things. Women have accumulated thoughts and desires within themselves, and only writing through $n u s h u$, they are free to express themselves. $N u$ shu is a tool, for the women to be able to voice out their opinions. It is the only way to break free from the oppression without having to confront the men, and particularly, the society.

\section{CONCLUSION}

Based on the analysis, the first conclusion deals with the depiction of female subjectivity. In Lisa See's Snow Flower and the Secret Fan, the female subjectivity is depicted as a series of woman's action and behavior regarding their surroundings. See depicts the female subjectivity by describing how the female characters are able to think, to speak, and to act for themselves. In a midst of limited freedom, it is important for the female characters to acquire a sense of selfhood and personality. The second one concerns with the contributing factors to female subjectivity. In the novel, female subjectivity is triggered by women's oppression (exploitation, marginalization, powerlessness, violence). Women's oppression has been a real issue in countries where patriarchal system is present. As a result of oppression, often, it leads to some kind of rebellion through resistance action. The acts of resistance are present in the form of silence resistance and through $n u$ shu writing-telling stories in life and expressing their voices. Based on the study, it is suggested to another researcher to look at how the female subjectivity is seen through psychological aspect and what entails as the consequences.

\section{References}

[1] Butler, Judith, Gender Trouble: Feminism and the Subversion of Identity. New York and London: Routledge. 1999.

[2] Even Zohar, Itamar, Culture planning and cultural resistance in the making and maintaining of entities. Tel Aviv University. 2002.

[3] Heldke, Lisa and Peg O'Connor, Opression, Privilege, \& Resistance Theoretical Perspectives on Racism, Sexism, and Heterosexism. McGraw Hill. 2003.

[4] Hollander, Jocelyn A and Rachel L. Einwohner, "Conceptualizing resistance". Sociological Forum, vol. 19, no. 4, pp. 533-544, 2004.

[5] Irigaray, Luce, This Sex Which is Not One, New York: Cornell University Press. 1985.

[6] Man Rhim, Soon, "The status of women in China: yesterday and today", Asian Studies Journal, vol. 20, pp. 1-44, 1982.

[7] Mansfield, Nick, Theories of the Self From Freud to Haraway, New South Wales: Allen \& Unwin. 2000.

[8] Morton, Donald and Mas'ud Zavarzadeh, Texts for Change: Theory/Pedagogy/Politics, University of Illinois Press. 1991.

[9] Soza, Amand, Girls will be girls: discourse, poststructuralist feminism and media presentations of women, Boise State University. Thesis. 2004

[10] Vinthagen, Stellan and Anna Johansson, "Everyday resistance: exploration of a concept and its theories", Resistance Studies Magazine no. 1, University of Sweden, 2013. [11] Weedon, Chris, Feminist Practice and Poststructuralist
Edition,
Wiley 